\title{
Brasília em Nicolas Behr: amnésia colossal e desastrada
}

\author{
Filipe Manzoni
}

RESUMO: Nosso trabalho propõe uma investigação do caráter amnéstico inerente ao projeto modernista de Brasília e as subversões nele operadas pela poesia de Nicolas Behr. Interessa-nos observar o quanto a poesia de Nicolas ironiza as pretensões à ausência de memória do projeto urbanista da capital ao mesmo tempo em que busca brechas para a constituição de uma memória urbana alternativa. Perpassaremos, para tanto, alguns aspectos "desastrados", negligenciados pela história da cidade (a sua pedra fundamental, sua monumentalidade e a origem de suas cidades-satélites), buscando flagrar aberturas possíveis para a fundação de uma memória e de uma história "não planejada".

PALAVRAS-CHAVE: Nicolas Behr; memória urbana; Brasília.

\begin{abstract}
This article aims to analyze the amnesiac aspect of the modernization project of Brasilia, as it seems to be exposed and subverted by the poems of Nicolas Behr. The main objective is to canvass the failures, explored by Behr, in the oblivion of the historical process of planning and development of the city. Within, this essay will reconsider some neglected images of Brasilia's history (its fundamental stone, its monumentally and the origin of its satellite-cities) as possible turning points for an invention (or a rediscovering) of a memory of Brasilia.
\end{abstract}

KEYWORDS: Nicolas Behr; urban memory; Brasília. 


\section{UM KOLOSSÓS DESASTRADO}

Conforme nos narra James Holston em A cidade modernista,${ }^{1}$ o projeto de transferência do centro administrativo do Brasil para o interior é mais antigo do que a própria consolidação do país como estado independente, podendo ser remontado em trechos de falas do marquês de Pombal e de Tiradentes ainda no século xix. Oficializado pela primeira vez já na primeira Constituição federal em 1891, o projeto de transferência da capital assume um caráter de empresa decisiva na modernização do país, revestindo-se com uma mitologia de "terra prometida", fonte de riquezas inconcebíveis, que polarizaria definitivamente o desenvolvimento da nação. ${ }^{2}$

Esse estatuto mitológico da construção de Brasília transparece nos mais diversos discursos sobre a capital. Se nos voltamos para a apreciação de um arquiteto como Yves Bruand, por exemplo, encontramos a mesma indissociabilidade de Brasília para com sua carga simbólica, que, mais do que uma afirmação definitiva da arquitetura modernista brasileira, se propõe como um projeto brasileiro de modernização utópica:

A cidade, desde o começo, assumiu um duplo papel material e psicológico; de um lado, polo de atração e base de partida para uma conquista ulterior, e, do outro, símbolo das possibilidades futuras do país e da união nacional, Brasília foi a expressão de uma vontade de afirmação da grandeza e vitalidade do Brasil, uma prova de sua capacidade de empreender e da confiança em seu destino, uma ideia-força capaz de galvanizar a opinião. ${ }^{3}$

Essa "ideia-força" ou "ideia Brasília" (segundo Holston)4 de modernização e reinvenção do país a partir da transferência da capital atravessa os mais diversos momentos e projetos modernistas em curso nos duzentos anos que separam as intuições do marquês de Pombal da campanha presidencial de Juscelino Kubitschek. Porém, um episódio, no meio dessa verdadeira "história das fundações de Brasília", nos chama especial atenção:

1. holston, James. A cidade modernista. Uma crítica de Brasília e sua utopia. Tradução de Marcelo Coelho. São Paulo: Companhia das Letras, 1993.

2. Idem, pp. 24-5.

3. BRuand, Yves. Arquitetura contemporânea no Brasil. Tradução de Ana M. Goldberger. São Paulo: Perspectiva, 1981, p. 353.

4. Holston, James. Op. cit., p. 24. 
durante o governo de Epitácio Pessoa, "uma pedra fundamental foi simbolicamente colocada no lugar onde hoje existe uma cidade-satélite". ${ }^{5}$ Nossa proposta de leitura sobre Brasília e memória poderia ser situada com base em duas questões que se desdobram desse curioso evento.

Primeiramente, buscamos ler nesse gesto simbólico não apenas a afirmação de um projeto de modernização, mas sua incontornável contraface: um flagrante apagamento histórico. A pedra fundamental, cuja pretensão é afirmar, em meio a um planalto "vazio" (conforme diversos dos relatos sobre Brasília na década de 1960 enfatizam), o "marco-zero" de um "novo Brasil", marca igualmente uma negação do "velho Brasil" que está em volta.

De fato, toda a carga simbólica que a transferência da capital assume no Brasil da década de 1950 é descrita por Holston como uma deliberada "tábula rasa" da realidade brasileira. Esse projeto de apagamento histórico, mais do que um efeito colateral, constitui o próprio centro do argumento desenvolvimentista, ele mesmo portador de uma linhagem na história brasileira:

Essa legitimação combinava uma mitologia do Novo Mundo e a teoria do desenvolvimento, associando a fundação da capital à fundação de um novo Brasil. Ao longo da história brasileira, essa vinculação teve vários nomes, incluindo Nova Lisboa, Petrópole, Pedrália, Imperatória, Tiradentes, Vera Cruz e, por fim, Brasília - cada nome simbolizando as intenções de seus propositores. Kubitschek e seus arquitetos amalgamaram essas intenções numa única proposição retórica. ${ }^{6}$

O mito do novo mundo faz da pedra fundamental de Brasília, portanto, a base de uma nova sociedade e, ao mesmo tempo, uma espécie de kolossós da antiga, isto é, uma pedra tumular que encerraria a imagem do Brasil pré-moderno como quem cumpre um rito funerário. O kolossós grego, amplamente estudado por Jean-Pierre Vernant, se coloca, segundo o autor, como marco de um rito funerário cujo objetivo é banir do mundo dos vivos o phasma, ${ }^{7}$ a presença fantasmática do morto. O rito funerário se dá, portanto,

\footnotetext{
5. Idem, p. 25 .

6. Idem, p. 27 .

7. VERnAnt, Jean-Pierre. Figuras, ídolos, máscaras. Tradução de Telma Costa. Lisboa: Editorial Teorema, 1991, pp. 21-5.
} 
como um corte entre dois elementos: "uma face visível, localizada, dura e permanente como pedra; [e] uma face invisível, ubíqua, inalcançável e fugidia como a psuché, exilada no domínio do alhures".

Nossa proposta é, nesse sentido, ler não apenas na pedra de Epitácio Pessoa, mas na própria concepção utópica de Brasília, o que aí é um rito funerário, uma tentativa de sepultamento, pelo projeto urbano modernista, de uma história fantasmática do Brasil. Brasília se converte, assim, em uma ampliação de sua pedra fundamental: uma face visível, localizada, dura e permanente - um kolossós - cujo objetivo último é a negação de sua história fantasmática - o phasma -, exilada no domínio de alhures.

A associação, estabelecida por Vernant, entre o phasma e a psuché ainda nos concede um novo sentido à emblemática frase escrita por Simone de Beauvoir a respeito de Brasília em 1960: "Atravessamos mais de mil quilômetros através de uma região mortalmente desértica para chegar a esse lugar. Mas vou deixar Brasília com o maior prazer - a cidade nunca terá alma, coração ou sangue".

A frase de Simone de Beauvoir é anterior à inauguração da cidade, mas parece flagrar um aspecto decisivo de seu projeto, que cremos estar diretamente relacionado à sua pretensão a-histórica e amnéstica. Não é fortuito que James Hillman, em seu Cidade e alma,${ }^{10}$ propõe a memória como uma das figurações possíveis para a "alma" de uma cidade:

Uma terceira ideia tradicional de alma tem a ver com memória emotiva. Experiências emocionais, coisas que importaram para você em sua própria vida; coisas importantes para a comunidade, sua história. [...] As cidades antigas foram originalmente construídas sobre o túmulo ou a sepultura do fundador da família, do clã ou da cidade. E assim encontramos as memórias dos heróis locais nos nomes dos lugares, que são um tributo às emoções que aconteceram no passado e sobre as quais foi fundada a cidade. ${ }^{11}$

8. Idem, p. 24 .

9. BEAUvoir, S. apud BeHr, Nicolas. BrazíliA-Z cidade-palavra. Brasília: Nicolas Behr, 2014, p. 12, grifo nosso. 10. Hillman, James. Cidade \& alma. Coordenação e tradução de Gustavo Barcellos e Lúcia Rosenberg São Paulo: Studio Nobel, 1993.

11. Idem, p. 39. 
Se Hillman ressalta que as cidades antigas eram construídas sobre os túmulos dos fundadores para preservar sua memória, em Brasília, a pedra fundamental se coloca como uma tentativa de fundar uma cidade sobre um túmulo vazio, ou sobre a negação de sua própria memória (e até mesmo da história das tentativas de afirmação de um novo Brasil a partir de uma terra prometida). Parece ser essa paradoxal fundação de uma cidade pretensamente sem memória que está no centro do diagnóstico fatalista de Simone de Beauvoir.

Porém, o que nos interessa não é reenfatizar a colossalidade ou a boa execução do projeto. De fato, trata-se justamente do oposto. Interessa-nos reler a "ideia Brasília" pelas falhas de sua execução, pelo retorno ou invenção de uma memória marginal não planejada, ilustrada, em nossa imagem-síntese da pedra fundamental de Brasília, pela sua atual posição geográfica em uma cidade-satélite (e aqui nos encontramos com nosso segundo desdobramento de leitura do gesto de Epitácio Pessoa).

Nesse contexto, a poesia de Nicolas Behr parece colocar-se quase como um projeto para um "anti-kolossós". Suas obras, em sua maioria livretos artesanais produzidos e vendidos pelo poeta de mão em mão desde meados da década de 1970, possuem quase uma obsessão por Brasília, onde Nicolas morou praticamente a vida inteira. Se é verdade que a própria materialidade dos livros de Nicolas - isto é, a precariedade das edições mimeografadas - poderia ser lida, por si mesma, como índice de uma produção que, em seu caráter dispersivo e subversivo, se contrapõe à pretensão colossal do projeto urbano da capital, sua temática parece responder ainda mais diretamente a esse "túmulo vazio" do discurso fundacional de Brasília e à necessidade de inventar uma alma para a cidade inventada. De fato, Nicolas responde diretamente ao diagnóstico de Simone de Beauvoir no verbete "alma" de seu BrazíliA-Z cidade-palavra: "a praga que Madame de Beauvoir rogou contra Brasília não vingou. Errou feio"."

De nossa parte, cremos que não se trata tanto de um erro quanto de um acerto preciso no alvo errado. Simone tece um perfeito diagnóstico do intento do projeto modernista em sua carga de apagamento histórico, mas acredita demais em sua eficácia, deixando de lado seus restos e esquecendo as suas falhas e margens não planejadas. É nesse contexto que buscamos ler a produção poética de Nicolas Behr sobre Brasília, ${ }^{13}$

\footnotetext{
12. BEHR, Nicolas. Op. cit., p. 12.

13. Caberia ainda ressaltar o quanto as precárias edições mimeografadas nas quais a obra de Nicolas circulou durante as décadas de 1970 e 1980 poderiam ser lidas como um índice de uma produção que se alinha mais a um caráter dispersivo (e, naturalmente, subversivo), em oposição ao "colossal" projeto urbano de Brasília.
} 
na medida em que ela se constrói como discurso do desastre do projeto urbano modernista, de maneira a transformar o diagnóstico de Beauvoir em um erro.

Subverter o kolossós, esse projeto a-histórico de silenciamento monumental, se coloca, na poesia de Nicolas Behr, como uma forma de abrir o túmulo da cidade, liberar seus fantasmas sufocados pela pretensão de uma "cidade inventada" e convocá-los para a história. Trata-se, finalmente, de reescrever (ou, talvez mais precisamente, de reler) a fundação da cidade de forma que a sua pedra fundamental não figure em seu perfeito funcionamento, mas sim em sua face desastrada, isto é, desde sua reapropriação pela margem excluída do processo de modernização.

\section{MONUMENTOS SEM MEMÓRIA VERSUS MONUMENTO AOS ESQUECIDOS}

O aspecto monumental da arquitetura de Brasília é um dos pontos fundamentais da particularidade de sua concepção. Não por uma questão de proporções absolutas (vale lembrar que a altura dos prédios de Brasília é predominantemente reduzida para uma grande metrópole), mas por uma questão de percepção e contraste. Após analisar as relações figura-fundo presentes nas cidades pré-modernas e nos planos modernistas, James Holston encerra sua reflexão especificamente com este diagnóstico sobre os prédios da capital: "como uma escultura isolada, todo edifício agora aspira a ser reconhecido como monumento". ${ }^{14}$ Os prédios são monumentais - vocábulo que não sem certa ironia possui como sinônimo no dicionário Houaiss o "colossal" - porque, tal qual os monumentos, se dispõem isolados sobre um fundo vazio.

É sintomático, nesse sentido, o quanto a poesia de Nicolas Behr recorrentemente caracteriza Brasília não desde sua arquitetura mas desde seu vazio: "a cidade é isso mesmo/ que você está vendo/ mesmo que você/ não esteja vendo nada”, ${ }^{15}$ ou ainda:

\footnotetext{
Em meio ao vazio do cerrado

construiu-se uma cidade vazia

habitada por pessoas vazias

que circulam por avenidas vazias

em carros de pneus vazios. ${ }^{16}$
}

\footnotetext{
14. HOLSTON, James. Op. cit., p. 139.

15. BEHR, Nicolas. Braxília revisitada. Brasília: Nicolas Behr, 2004, vol. 1, p. 82.

16. Idem, p. 57.
} 
Nicolas estabelece um paralelo entre o processo de revestimento discursivo do cerrado como um "grande vazio" e a proliferação de vazios do plano piloto. Trata-se de ler, nesse sentido, o que na monumentalidade da arquitetura depende de um esvaziamento do seu entorno: tanto a cidade propriamente dita (uma ilha de concreto "em meio ao vazio do cerrado") quanto cada um de seus edifícios são tão mais monumentais quanto mais seu fundo for percebido como vazio.

O processo de esvaziamento inerente ao monumental (ou, para retomarmos nossa proposição inicial, ao colossal) atua, porém, não apenas no nível figural da percepção dos edifícios, mas também na sua vivência paradoxal. Trata-se, afinal, de uma "cidade monumental" cujos primeiros moradores (vale lembrar que grande parte dos poemas de Nicolas foram escritos nos primeiros dez anos de ocupação de Brasília) não possuíam qualquer vínculo mnemônico com sua monumentalidade:

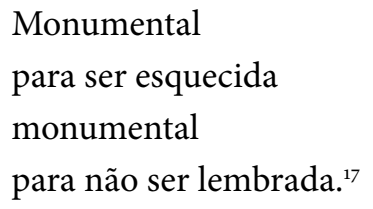

Nicolas retoma, nesse sentido, a própria etimologia da palavra "monumento", provinda do verbo latino monere, "advertir, lembrar, avivar", para apresentar o estatuto paradoxal de uma arquitetura que prolifera "monumentalidades" desatreladas de quaisquer memórias comunitárias. Seu efeito é, mais propriamente, o do apagamento da memória, visto que a cidade inteira foi construída (desde seu marco zero) sob um signo de afirmação de um novo país, de uma tábula rasa para o futuro.

Se a cidade como um todo tende para a "monumentalidade" em sua arquitetura, o paradoxo "monumento $v s$. memória” no projeto de Brasília ainda é especialmente problematizado pelos poemas de Nicolas a partir da profusão de monumentos e memoriais propriamente ditos. Renato Cordeiro Gomes, em seu Todas as cidades, a cidade, ${ }^{18}$ ressalta o quanto os monumentos são parte indispensável para o estudo simbólico das cidades, na medida em que são "a mais completa autorrepresentação da cidade e sua

17. Idem, p. 28.

18. GOMEs, Renato Cordeiro. Todas as cidades, a cidade: literatura e experiência urbana. Rio de Janeiro: Rocco, 2008. 
história". ${ }^{19}$ Ao nos voltarmos, porém, para a Brasília de Nicolas Behr, essa autorrepresentação se dá, novamente, em uma chave de apagamento da memória:

Paiê,

que monumento é aquele?

aquele é o monumento

ao monumento desconhecido. ${ }^{20}$

É, nesse sentido, o mesmo modelo do kolossós o que parece dar o tom dos monumentos na poesia de Nicolas Behr. A “autorrepresentação da cidade e sua história" opera como uma autorrepresentação do gesto de apagamento de sua própria história, e não como um marco mnemônico propriamente dito. Tudo se passa como se os monumentos de Brasília se colocassem como um dos mais radicais expoentes da clássica tese benjaminiana segundo a qual "nunca houve um documento da cultura que não fosse simultaneamente um documento de barbárie" :21 a apoteose da arquitetura modernista, a construção de uma cidade inteira projetada pela mão de um arquiteto, se coloca sob o signo da barbárie de um flagrante apagamento histórico.

Caberia ainda ressaltar o quanto parece operar no poema um segundo (embora mais sutil) deslocamento da relação figura-fundo. O que ocupa o primeiro plano é o diálogo corriqueiro entre pai e filho que ironiza a proliferação de monumentos na capital, de maneira que o monumento propriamente dito é relegado à distância de um pronome demonstrativo que o mantém indistinto e anônimo. É como se o poema buscasse captar, dessa forma, um instante possível de inversão do estatuto monumental da cidade, colocando em primeiro plano o mesmo tipo de experiência corriqueira que precisa ser apagada para que o monumento seja, de fato, "monumental".

A noção de um "monumento desconhecido" ou de um monumento aos desconhecidos aparece ainda reiteradamente nos poemas de Nicolas. Essa tentativa de - novamente de maneira benjaminiana - ler a história a contrapelo, isto é, retirar o kolossós e soltar os fantasmas das histórias apagadas, figura como a evocação de um

19. Idem, p. 28.

20. BEHR, Nicolas. Laranja seleta. Rio de Janeiro: Língua Geral, 2007, p. 71.

21. BENJAMIN, Walter Magia e técnica, arte e política: ensaios sobre literatura e história da cultura. Tradução de Sergio Paulo Rouanet. São Paulo: Brasiliense, 2012, p. 245. 
monumento alternativo, ou de um monumento em sentido estrito, que representasse a história coletiva da fundação da cidade à revelia do seu apagamento oficial:

\author{
Neste país sem memória \\ também vou construir um memorial \\ em memória de todos \\ os construtores de cidades \\ memorial JKLMNOPQRSTUVXZ22
}

Da mesma maneira que o intento de recuperação da história perdida dos construtores mortos leva José Saramago, em seu Memorial do convento, ${ }^{23}$ a abarcar o inumerável dos fantasmas pela escolha de um nome para cada inicial possível do alfabeto, Nicolas busca também recuperar o inumerável pela sobreposição de iniciais. Trata-se de uma maneira de escapar de um modelo "monumental" de história que opera pela centralização em uma figura - e pelo decorrente apagamento de uma miríade de nomes -, através de uma possibilidade de leitura da multiplicidade apagada pelo mero ato de erguer um monumento.

Nicolas não propõe, porém, erguer um "novo monumento", mas sim sobrepor o seu memorial de iniciais apagadas às célebres iniciais de Juscelino Kubitschek, construindo seu memorial como uma releitura ou ressignificação do icônico "memorial JK". O poema toma posse, assim, do museu monumental, acrescentando às suas iniciais as iniciais dos construtores esquecidos, apagados da história oficial, e relendo o Memorial $\mathrm{JK}$, esse monumento que constitui um dos cartões-postais de Brasília, pelo que nele é o avesso do monumento, isto é, pelo que nele é puro apagamento histórico.

O Memorial JK propriamente dito não deixa dúvidas quanto ao modelo de memória com o qual está comprometido: trata-se de um museu que contém os restos mortais do ex-presidente. Projetado por Oscar Niemeyer e situado em um dos pontos mais altos da cidade, o Memorial JK traz ainda a figura singular de Juscelino Kubitschek em uma estátua de bronze de 4,5 metros de altura, despontando como efígie vitoriosa do presidente "construtor de cidades".

Se reiteramos diversas vezes a íntima relação entre a fundação da capital e o estatuto amnéstico de apagamento de sua história, fica claro no Memorial jK o quanto o apagamento da história de Brasília deixou as lacunas específicas a serem preenchidas futuramente pelos

\footnotetext{
22. BEHR, Nicolas. O bagaço da laranja. Brasília: Nicolas Behr, 2009, p. 59.

23. Saramago, José. Memorial do convento. São Paulo: Companhia das Letras, 2013.
} 
seus heróis oficiais. Se James Hillman ressaltava que as cidades antigas foram fundadas sobre o túmulo de seus fundadores, Brasília incorreu em uma inversão irônica: a cidade é fundada pretensamente sobre um túmulo vazio para que, duas décadas após a sua inauguração (o memorial só foi inaugurado em 1981), esse túmulo seja ocupado pelo seu "fundador" heroico.

É precisamente esse estranho "espaço fundacional a posteriori" que Nicolas busca reler não como uma forma de simplesmente deslegitimar a mitologia oficial que coloca JK como um "construtor de cidades" - afinal, as suas iniciais estão ali também -, mas como uma subversão do próprio modelo histórico inerente ao monumental. Interessa, mais do que operar pela reescritura da história fundacional de Brasília, praticar uma pluralização de suas alternativas de releitura. Ao invés de substituir os heróis oficiais, destituir a heroicidade que se constrói a partir da monumentalidade amnéstica.

\section{REPETIR A HISTÓRIA ABSURDA E CONTAR O ABSURDO DA HISTÓRIA}

A mitologização da figura de JK é ainda um elemento frequentemente ironizado pela poesia de Nicolas, na medida em que ela reveste o ex-presidente de uma carga simbólica de mártir católico. Essa simbologia, que remonta ao próprio Plano Piloto de Lúcio Costa - quando este relaciona a fundação da cidade com o sinal da cruz, "nasceu do gesto primário de quem assinala um lugar ou dele toma posse: dois eixos cruzando-se em ângulo reto, ou seja, o próprio sinal da cruz" ${ }^{24}$-, opera como uma das principais linhas de força de associação de Brasília a uma terra prometida. Sob o lastro dessa analogia salvacionista, JK figura, na poesia de Nicolas, como um messias católico, ao passo que Lúcio Costa aparece como um apóstolo evangelista:

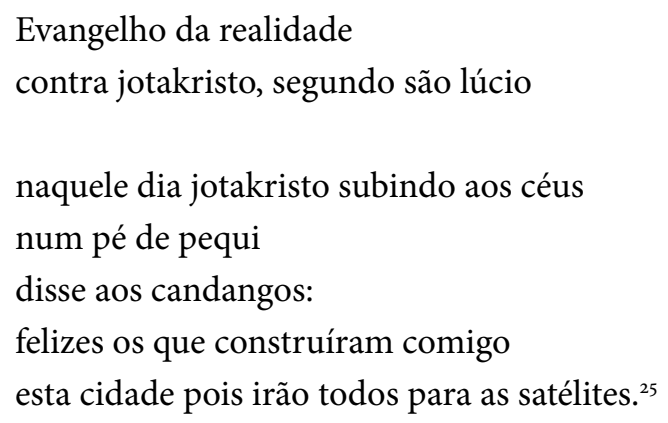

24. Costa, apud holston, James. Op. cit., p. 77.

25. BEHR, Nicolas. Laranja seleta, cit., p. 89. 
Nicolas se apropria, nesse sentido, do aparato discursivo de mitologização utilizado tanto pelo texto do Plano Piloto de Lúcio Costa quanto pela campanha presidencial de Juscelino Kubitschek, ironizando a pretensa "naturalidade" do gesto fundacional e desmascarando o desdobramento segregacionista do projeto. Juscelino e Lúcio Costa (ou ainda, em outros poemas, Oscar Niemeyer) figuram, nesse revestimento irônico, como elementos de uma espécie de cruzada para a modernização do país que apenas acaba por reconstruir a sua mesma desigualdade fundacional.

Se já abordamos a "monumentalidade" da cidade enquanto um deliberado esvaziamento de seu fundo de percepção, o discurso de mitologização da fundação converte-se, por si mesmo, em um gesto eminentemente monumental, na medida em que o Plano Piloto de Lúcio Costa apresenta

a fundação de Brasília como se esta não tivesse história, como se não fosse uma resposta tanto às condições socioeconômicas do Brasil em 1957, quanto ao modernismo na arquitetura. Na verdade desistoriciza sua ideia de Brasília, ocultando as intenções de mudança social sob uma mitologia de princípios arquitetônicos universalizantes, de cidades antigas e técnicas consagradas de planejamento. ${ }^{26}$

Brasília - e essa é algo como a tese central da obra de Holston - inventa para si um passado mítico que a conecta a gestos imemoriais em uma estratégia de dissociar sua fundação do seu próprio condicionamento histórico. O discurso oficial da fundação da capital busca colocar no lugar do túmulo vazio os mitos que ela mesma constrói (conforme fica evidente no caso do Memorial JK). Nicolas, por sua vez, parece ironizar essa pretensão a-histórica a partir de uma série de passados mitológicos absurdos, situando Brasília como uma espécie de elo perdido entre a Antiguidade clássica e o Brasil da década de 1950, uma extrapolação da mitologização do projeto:

Fósseis de mísseis, pegadas de heitor e ulisses, metralhadoras de ossos e granadas de pedra polida atestam que a guerra de troia realmente aconteceu nas proximidades do lago Paranoá,

26. HOLSTON, James. Op. cit., p. 67. 
quando este ainda se chamava mar egeu

a frase "impossível agradar a gregos e goianos"

ainda hoje em uso, é um resquício

dos tempos homéricos. ${ }^{27}$

O deliberado anacronismo de Nicolas como que responde ao anacronismo "oficial" do Plano Piloto de Lúcio Costa, isto é, à tentativa de armar uma memória de Brasília sob um pano de fundo do imemorial. A estratégia é, nesse sentido, semelhante à que abordávamos com relação à releitura do monumental desde seu vazio: trata-se de uma extrapolação dos vínculos míticos e imemoriais através da "revelação" de rastros absurdos de cidades antiquíssimas em fictícias escavações no planalto Central.

Outra alternativa da qual a poesia de Nicolas lança mão para ironizar o discurso anacrônico oficial é a sua tentativa de figuração ex nihilo. Se o Plano Piloto propriamente dito começa com uma justificação de que a solução não foi procurada mas já apareceu pronta, essa "espontaneidade" - uma "justificação natural para aquilo que é motivado historicamente ${ }^{28}$ - faz de Brasília, na obra de Nicolas, algo como uma cidade fora do tempo que não tem como memória mais do que uma projeção, no passado, de sua própria realidade burocrática:

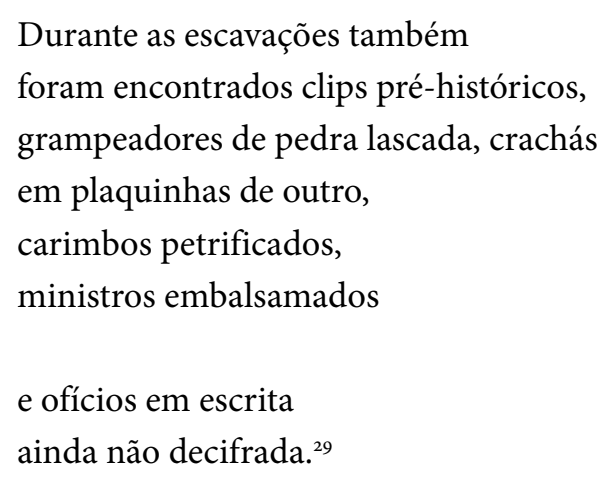

Se a cidade se quer sem passado, Nicolas parece pôr em primeiro plano o absurdo prático dessa pretensão, propondo prospecções arqueológicas que revelam Brasília como

27. BEHR, Nicolas. Op. cit., p. 61.

28. Holston, James. Op. cit., p. 77.

29. Idem, p. 73. 
única causa de si mesma, como bem-sucedida tábula rasa a partir da qual a cidade se inscreveu no centro do Brasil. Ao se escavar a cidade modernista, se seu projeto amnéstico fosse levado às últimas consequências, apenas se encontraria, portanto, a mesma cidade inscrita em suas camadas subterrâneas pré-históricas.

Partindo de uma tela de Paul Klee, Ein Blatt aus dem Städtebuch, de 1928, Renato Cordeiro Gomes propõe, em Todas as cidades, a cidade, uma imagem para o urbano que se torna interessante nesse cenário de escavações do passado de Brasília. Renato sugere que, tomada enquanto um texto, a cidade se ofereceria à leitura não inscrita em uma página, mas sim em um palimpsesto: uma sobreposição de diferentes camadas de escrita. A cidade seria, nesse sentido, uma textualidade na qual "se apagassem os registros de outras cidades que, por superposições sucessivas, embaralham os sentidos, dificultando a decifração de sua escrita"..30

Ler as cidades, isto é, decifrar seus textos, se transformaria, assim, em uma modalidade de "raspar essas camadas superpostas, a começar pelo desenho da cidade moderna [...] para que, num trabalho arqueológico, se possa recuperar a inscrição de outra cidade mais antiga". ${ }^{31}$ É claro que Renato Cordeiro Gomes toma o cuidado de não tomar essas dobras de cidades soterradas como um discurso preservado intacto, mas sim como um código indiscernível do próprio gesto de sua leitura, de maneira que o leitor "reconstrói a cidade enquanto texto e se inscreve nele, engendrando, em meio a este amontoado de signos da superfície da folha pergaminho, um traçado de uma possível legibilidade", ${ }^{32}$ fazendo com que, no limite, "decifrar/ler esta cidade é cifrá-la novamente, é reconstruí-la com cacos, fragmentos, rasuras, vazios, jamais restaurando-a na íntegra".33

Esse gesto de cifrar novamente o texto da cidade é especialmente subversivo no que diz respeito ao "texto" Brasília. Não apenas porque a metáfora de Renato Cordeiro Gomes pode ser levada às beiras da literalidade, já que Brasília foi pensada desde um texto - o Plano Piloto de Lúcio Costa -, mas também porque esse texto é um dos elementos principais de articulação da mitologia que opera pelo apagamento de qualquer vestígio anterior. Nesse sentido, recifrá-lo é mais do que recuperar cidades

\footnotetext{
30. GoMes, Renato Cordeiro. Op. cit., p. 38.

31. Ibidem.

32. Idem, p. 39.

33. Idem, p. 40.
} 
inscritas anteriormente, é pôr a nu o absurdo do projeto de uma cidade inventada e sem história.

Se nosso ponto de partida buscava ler o paradoxo histórico do discurso oficial de Brasília no gesto da colocação de sua pedra fundamental, cabe agora nos voltarmos para um segundo episódio rasurado da história da capital que se oferece como imagem interessante para situarmos a subversão, pela poesia de Nicolas Behr, do projeto modernista. Assim como o episódio da "pedra fundamental", trata-se de um acontecimento de caráter quase iconográfico.

\section{BABILÔNIA E A CIDADE LIVRE}

Não são poucas as caracterizações de Brasília como uma cidade que, além de não ter alma, não possui corpo (cabe relembrar a fala de Simone de Beauvoir, segundo a qual não apenas a cidade não teria alma, também lhe faltariam coração e sangue). É evidente o quanto essas duas instâncias são, na realidade, muito próximas; isto é, os motivos pelos quais a cidade não teria alma e pelos quais ela não teria corpo se confundem.

Um dos elementos centrais dessa dupla caracterização poderia ser identificado na concepção do espaço urbano de Brasília como uma extrapolação da eficiência do fluxo pelas rodovias que obliterou o espaço para toda experiência "não funcional" da circulação de pedestres. A "morte da rua", que se põe como ponto central no projeto de Brasília, é um dos elementos principais que revestem a cidade de um tom "frio" e "distante" que perpassa os relatos dos primeiros moradores da cidade na década de 1960. Se nos detivemos até agora em uma série de fantasmas históricos sequestrados sob o kolossós da cidade, é interessante observar o quanto o mesmo projeto urbano ainda parece perpetuar-se como um sequestro dos corpos em sua demanda de contato.

É significativo que essa demanda de contato se aproxime do que Jean-Luc Nancy situa, em seu "Imágenes de la ciudad", ${ }^{4}$ como a característica intrínseca à imagem central de todas as tentativas de mitologização das cidades. Se a invenção de uma linhagem fundacional, longe de ser uma exceção de Brasília, constitui, antes, a norma (embora seja evidente que Brasília apresenta uma extrapolação de difícil equiparação nesse sentido), Nancy sugere que a imagem fundamental de toda essa "proliferación exaltada de

34. NANCy, Jean-Luc. La ciudad a lo lejos. Buenos Aires: Manantial, 2013, pp. 51-73. 
los emblemas de la ciudad en tanto hipérbole de sí misma"35 é a imagem da Babilônia: "Si Babilonia fue 'la gran prostituta', es en gran medida porque la ciudad [...] levanta una reivindicación absoluta de goce. ${ }^{36}$

Nancy se volta para a precedência de um imperativo de gozo como fundamento da experiência da cidade, relacionando sua imagem mítica fundacional ao prostíbulo e ao bordel:

El burdel fue en principio una choza hecha de tablones, y designaba por consiguiente una construcción ligera, sencilla y más bien no citadina. De hecho, se suponía que las prostitutas sólo tenían licencia para ejercer en barrios periféricos formados de tales barracas [...]. Se trata de establecer con el burdel el contrapunto de la sacralidad elevada de la ciudad. ${ }^{37}$

Ao se colocar como uma cidade sem espaço para o contato entre os corpos, a "ideia Brasília" incorreria, portanto, em uma interdição da demanda mais fundamental da cidade: sua face babilônica. Essa interdição encontra ainda uma imagem interessante em um episódio da construção da cidade novamente pautado pelo contraste entre o esforço amnéstico do projeto modernista e seus resultados imprevistos. Durante a construção de Brasília, uma zona comercial liberada para a iniciativa privada foi permitida nos perímetros da cidade, ficando conhecida como "Cidade Livre". Tratava-se de uma pequena área delimitada no Distrito Federal para encorajar empresários a fornecerem produtos e serviços aos construtores da capital. Segundo Holston, "a combinação entre um governo laissez-faire e edificações temporárias de madeira fez da Cidade Livre algo como uma vila de faroeste americano, com a qual foi frequentemente comparada", ${ }^{38}$ uma única rua principal poeirenta, "palco de uma cultura esmagadoramente masculina de dinheiro vivo em quantidade, de ambição e sexualidade reprimida". 39

Holston ainda ressalta o quanto a prostituição era um dos principais atrativos da Cidade Livre para os candangos, população formada $86 \%$ por homens sem compa-

\footnotetext{
35. Idem, p. 68.

36. Ibidem.

37. Idem, p. 70.

38. HOLSTON, James. Op. cit., p. 227.

39. Ibidem.
} 
nheiras ou famílias, ${ }^{40}$ de forma que a Cidade Livre se configura precisamente como o cenário de "chozas de bordes" 41 relegadas às periferias, conforme abordado por Nancy. Uma vila com toda a carga babilônica e marginal, destinada a ser destruída (por isso a restrição às construções de madeira) assim que a cidade ficasse pronta.

Se ressaltamos o quanto a pedra fundamental de Brasília representava um kolossós desastrado, dada sua localização atual em uma cidade-satélite, essa mesma releitura "desastrada" se repete na rasura da pequena Babilônia brasiliense: a Cidade Livre foi uma das principais causas da consolidação da primeira cidade-satélite. Foram alguns dos seus moradores que fundaram uma ocupação que resistiu à imediata remoção, ao espalharem faixas que a rebatizaram "Vila Sara Kubitschek" - em um jogo de reapropriação de símbolos oficiais que não deixa de ter algo de cômico.

É precisamente esse jogo de reapropriações e retomadas de símbolos que ocorre à margem do discurso fundacional o que nos interessa na Cidade Livre. Trata-se de uma memória que, ao invés de ser erradicada pela máquina eficiente de modernização, sobrevive em suas margens, fazendo com que a "essência da cidade" se coloque lá onde a sua pedra fundamental está: em uma cidade-satélite, ou ainda nas falhas de planejamento e intermitências do projeto que revelam a persistência incontornável do não planejado.

É justamente uma cidade-satélite o foco da atenção de Nicolas Behr em um pequeno livreto, Oitopoemaspraceilândia ${ }^{42}$ de 2009. Não qualquer cidade-satélite, porém a maior delas, aquela que traz, na etimologia de seu nome, as marcas de seu caráter de resistência subversiva: Ceilândia deve seu nome à CEI, Campanha de Erradicação das Invasões, programa de remoções que atuou durante a década de 1970 no Distrito Federal.

Desde seu primeiro poema - "Ceilândia/ é a maior// Ceilândia/ é o centro// o resto é periferia" ${ }^{43}$-, Oitopoemaspraceilândia deixa evidente uma proposta de ler Ceilândia como um espaço de subversão dos discursos fundacionais da centralidade de Brasília. Ao cruzar os dois eixos no sinal da cruz, o Plano Piloto, inaugurando um centro, invariavelmente fundava uma margem: em última instância (e em macroescala),

40. Idem, p. 222.

41. A condição de que as construções fossem apenas de madeira era, inclusive, normativa: como a Cidade Livre estava destinada a ser destruída assim que Brasília fosse inaugurada, as construções de alvenaria eram proibidas.

42. BEHR, Nicolas. Oitopoemaspraceilândia. Brasília: Nicolas Behr, 2009.

43. Idem, p. 5 . 
essa margem era o próprio Brasil - negado no projeto de fundação de um Brasil novo; contudo, em um círculo mais reduzido, tratava-se dos trabalhadores para os quais a cidade era vetada. As cidades-satélites, mesmo antes de sua formação, trazem o sinal de um elemento de exclusão que possibilita a fundação da cidade enquanto centro, são o efeito codependente, embora não planejado, do "sinal da cruz" que assinala um lugar.

Ao propor Ceilândia como o centro, Nicolas evidencia a mudança de prisma pela qual busca ler o projeto de modernização. Trata-se da possibilidade de ler Brasília desde Ceilândia, na medida em que esta é o espaço de falha do kolossós, espaço da sobrevivência da memória que resiste à tábula rasa do projeto modernista. Trata-se, finalmente, de uma possibilidade de pôr no centro do Brasil uma memória feita do entrecruzamento de discursos e eixos outros que não os "monumentais":

Em ceilândia não se fez

a vontade do príncipe

sem maquete

sem maquiagem

a $\mathrm{W}_{3}$ da dor

atravessa a $\mathrm{L}_{2}$

do abandono

outros eixos

cruzam teus medos

ceilândia, inaugurada

sem discurso de JK. ${ }^{44}$

Filipe Manzoni é doutor em literatura pela Universidade Federal de Santa Catarina.

44. Idem, p. 8. 